\title{
LO HUMANO, LA DESHUMANIZACIÓN Y LA INHUMANIDAD; APUNTES FILOSÓFICO-POLÍTICOS PARA ENTENDER LA VIOLENCIA Y LA BARBARIE DESDE J. BUTLER.
}

\author{
THE HUMAN, THE DESHUMANIZATION AND INHUMANITY; \\ PHILOSOPHICAL-POLITICAL NOTES FOR THE UNDERSTANDING OF \\ VIOLENCE AND BARBARIE FROM J. BUTLER
}

Tomeu Sales Gelabert

Recibido: 06/01/2015

Aceptado: 10/03/2015

\section{RESUMEN}

El presente trabajo intenta comprender el proceso de deshumanización actual que legitima prácticas y acciones inhumanas. Dichas prácticas, que abren la puerta a la barbarie dentro del corazón de las propias democracias "desarrolladas" y "civilizadas" se sustentan sobre una eticidad que presupone un marco de representatividad de lo humano y no humano. Este marco permite y legitima prácticas excluyentes y violentas contra todos aquellos conceptualizados como "no humanos". La reversión de dicha inhumanidad requiere la articulación de una nueva ontología social y política alternativa, y una nueva concepción de la ciudadanía capaz de desestabilizar críticamente los marcos normativos deshumanizadores.

PALABRAS Clave: Deshumanización, violencia, inhumanidad, políticas de redefinición, ciudadanía.

\section{ABSTRACT}

This paper attempts to understand the current process of dehumanization that legitimizes practices and inhumane actions. Such practices, which open the door to barbarism within the heart of their own "developed" and "civilized" democracies, are based on a morality that presupposes a framework of representation of the "human" and "nonhuman". This framework enables and legitimizes exclusionary and violent practices against those conceptualized as "non-human". The reversal of such 
inhumanity requires the articulation of a new social and political alternative ontology, and a new conception of citizenship able to critically destabilize normative frameworks dehumanizing

KEYWORDS: dehumanisation, violence, inhumanity, redefinition policies, citizenship.

\section{INTRODUCCIÓN}

El esfuerzo filosófico-político por entender la dinámica social y política está ligado a las diferentes formas de acción política. La acción está encadenada al marco teórico y éste al mismo tiempo a la acción. Se trata de una dinámica dialéctica en que el marco teórico redefine el campo de la acción y ésta al mismo tiempo desestabiliza dicho marco. Así, las nuevas formas de acción pueden ser desestabilizadoras o bien afirmativas del marco político-social previo. Dicho de otra manera, la novedad no siempre es tan nueva como se presenta. Las nuevas formas de acción son nuevas en tanto que son capaces de reestructurar el discurso y desestabilizar las normas que hasta el momento han limitado la representatividad y la inteligibilidad.

El intento por comprender una pléyade de acontecimientos diversos, como: el aumento en el último año de las agresiones machistas, los inmigrantes encaramados horas y horas en la verja de Melilla y Ceuta al sol del infernal estío, el amontonamiento de cadáveres en las costas de las playas de Libia, las sepulturas sin nombre que se acumulan en Ceuta y Lampedusa, el aumento de las agresiones xenófobas, la aparición de la extrema derecha euroescéptica y nacionalista en Europa, las consecuencias excluyentes de las políticas de austericidio, así como la limitación de la universalidad de la atención sanitaria a los "nacionales", etc., interpelan críticamente los marcos y conceptos teóricos actuales. Estos funestos acontecimientos son difícilmente asibles desde marcos teóricos reduccionistas. La realidad es sumamente compleja, multidimensional y multicausal. Se ha de superar la disyuntiva teórica entre políticas de la identidad y políticas de la producción-distribución, o culturalistas y materialistas, ya que dicha discusión se enmarca dentro de un paradigma teórico binario y dicotómico, no siempre explicitado. La cultura es tan material como ideal y es imposible desembridar lo material y lo ideal en la cultura. Dicho de otra manera, la política centrada en la dinámica de la producción-

Análisis. Revista de Investigación filosófica, Vol. 2, n. ${ }^{\circ} 1$ (2015): 49-61 
distribución está tan ligada a la identidad, como ésta a la produccióndistribución.

Recogiendo la distinción que utiliza A. De Miguel para referirse a la violencia de género, podríamos hablar de forma más acertada de "políticas reivindicativas" y "políticas de redefinición". Las demandas de reconocimiento de identidad, como aquellas que piden un reconocimiento nacional diferencial o cierta identidad transexual, y las demandas de redistribución de los recursos vía implementación de derechos sociales de ciudadanía o críticas con el sistema social de producción, se entienden como "políticas reivindicativas"; es decir, acciones colectivas que "apelan a la solidaridad para promover o impedir cambios sociales" (DE Miguel 2005, p. 3). Mientras que por otro lado, se encuentran las "políticas de redefinición", aquellas que proponen una "ruptura de los límites del sistema de normas y relaciones sociales en el que se desarrollada su acción (...), la subversión de los códigos culturales dominantes" (Ibíd.). Desde esta perspectiva se supera el dilema entre políticas de la identidad y políticas de la producción-distribución que encalló tanto el debate teórico-político en la década de los 90 y principios del 2000 (FrASER 2008). Ambas perspectivas no son independientemente exhaustivas ni excluyentes entre sí, sino que se relacionen mutuamente.

El objetivo de este trabajo es metapolítico; intentar esbozar el marco categorial que determina la inteligibilidad, y como tal la posibilidad de la política y de la acción política. Este marco categorial circunscribe aquello que es o puede categorizarse como humano. Los procesos de humanización y deshumanización enmarcan la moralidad y la acción política, legitimando o ilegitimando ciertas exclusiones y violencias hacia determinados colectivos. La inhumanidad es producto de la deshumanización del otro, justificando políticas de inmigración, de austeridad o invisibilizando ciertas formas de violencia.

Se trata de observar cómo funciona esta marco categorial metapolítico que permite, estabiliza y legitima ciertas representaciones en la ciudadanía, mientras que otras no son permitidas y por tanto se invisibilizan. Este marco y su funcionalidad social y política deben ser aprehendidos críticamente y desestabilizados a partir de otros marcos alternativos que impidan ciertas formas de exclusión y violencia. De la mano de J. Butler, se puede reestructurar dicho marco de lo humano como aquello precario que se precariza; es decir, la distribución social y política diferencial de la precaridad. Entendido lo humano como aquello precario y frágil se podrá comprender que una ciudadanía crítica no sólo es aquella que abroga por formas de acción directa y alternativa, sino 
también aquella que desestabiliza desde la igualdad normativa los marcos de representatividad e inteligibilidad de lo político.

\section{DE LA NORMA AL MARCO}

Butler distingue entre "normas" y "reglas"; éstas últimas son concreciones y o positivizaciones de las normas. En el primer caso nos encontramos con instituciones sociales y en el segundo caso con leyes positivas. En todo caso, las normas no se agotan en las reglas que las encarnan o concretan (BUTLER 2004b, p. 67). De la mano de Foucault, Butler entiende la norma no como un producto intersubjetivo, sino como una estructura discursiva previa al sujeto y que al mismo tiempo lo estructura. El poder regulador de la norma "no sólo actúa sobre el sujeto preexistente, sino que también labra y forma al sujeto (...), estar sujeto a un reglamento es también estar subjetivado por él, es decir, devenir como sujeto precisamente a través de la reglamentación” (Ibíd., p. 68). La norma es previa al sujeto y éste queda constituido como sujeto en la norma. Fuera de la norma no hay posibilidad de subjetivación. La norma "rige la inteligibilidad, permite que ciertos tipos de prácticas y acciones sean reconocibles como tales imponiendo una red de legibilidad sobre lo social y definiendo los parámetros de lo que aparecerá y lo que no aparecerá dentro de la esfera social" (Ibíd., p. 69). La norma que sujeta al mismo tiempo que forma marca los límites de aquello que puede ser percibido como un objeto social. Encuadra la aparición del fenómeno social, utilizando terminología kantiana. La norma es una especie de condición de posibilidad de toda acción, en tanto que ésta es fruto de una percepción determinada. No obstante, hablar de norma en sentido genérico sitúa el debate en un plano sumamente abstracto. Cuando se habla de norma, se refiere a las normas de parentesco, normas de género, normas que determinan lo humano, etc. Normas que fijan las instituciones sociales y las leyes socio-políticas concretas en un momento histórico dado, pero que no quedan agotadas por ellas. El patriarcado podría entenderse también como una norma.

Hay que destacar dos cuestiones antes de seguir. La primera, la norma al delimitar el campo de la "legibilidad", como dice Butler, no significa que determina total y mecánicamente el sujeto, sino que lo condiciona. Condición que no determinación mecánica, permite cierta autonomía y cierta distancia crítica del sujeto frente a las normas que lo han constituido como tal. En términos de la filosofía subjetivista de la identidad, la libertad del sujeto queda 
garantizada. Pero, no se trata de una libertad absoluta, sino que ésta está encuadrada por unos condicionamientos socio-político. Condicionamientos que al ser constitutivos del sujeto son al mismo tiempo externos e internos al sujetos. La diferencia entre aquello subjetivo y objetivo queda diluida. Sólo puede ser concebido como una diferenciación más entre otras, producto de la norma y como tal, lábil e históricamente cambiante.

La segunda cuestión central se refiere a la universalidad y atemporalidad de la norma. Aquí Butler critica la distinción estructuralista lacaniana y de C. LéviStrauss entre "posiciones simbólicas" y "normas sociales". Para los estructuralistas, las "normas simbólicas no son lo mismo que las normas sociales" (Ibíd., p. 71). Las normas simbólicas son concebidas como previas y constitutivas a las sociales. Fruto de una determinada estructura de parentesco o del lenguaje en que el sujeto ocupa una posición. Dichas estructuras son binarias, atemporales e independientes del sujeto, según el estructuralismo. En contraste, Butler sostiene una posición que intenta superar el estructuralismo al criticar la distinción entre normas simbólicas y normas sociales. Para ella, "la distinción entre la ley simbólica y la social no puede sostenerse en último término, (...) lo simbólico mismo es una sedimentación de las prácticas sociales" (Ibíd., p. 73). Superada la distinción entre normas simbólicas y normas sociales. Sólo quedan las normas, que no se agotan en las instituciones sociales y prácticas en que se concretan, pero que éstas alteran y transforman la norma. La norma es un producto socio-político sedimentado y estabilizado, es decir históricamente producido y sujeto al cambio, a partir de la concreción social de la misma norma. En este sentido, Butler supera el estructuralismo para defender una posición que se ha llamado postestructuralista, pero que bien podría ser calificada de dialéctica. La norma como producto de la práctica social, que al mismo tiempo la condiciona y está sujeta a las alteraciones que puede producir dicha práctica social.

Desde la posición postestructuralista butleriana la práctica social está condicionada por unas normas que preexisten a dicha práctica, que condicionan la agencia del sujeto, pero que no lo determinan indefectiblemente. La crítica permite superar y alterar las normas estructuradoras del campo de representatividad de lo social, previas a cualquier práctica o acción política. "El "yo" que soy se encuentra constituido por normas y depende de ellas, pero también aspira a vivir de maneras que mantengan con ellas una relación crítica y transformadoras. Esto no es fácil, porque, en cierta medida, el "yo" se convierte en algo que no puede conocerse, 
amenazado por su inviabilidad con ser deshecho completamente en cuanto deje de incorporar la norma mediante la cual este "yo" se convierte en totalmente reconocible" (Ibíd., p. 16). La indefectible distancia crítica que el yo marca respecto a las normas que lo constituyen muestra que lo que es él no es del todo conocido y asible, ya que es más de lo que uno cree ser, y al mismo tiempo está continuamente desestabilizándose, deshaciéndose. La crítica social no sólo desestabiliza el entramado social, sino que altera al propio sujeto. El sujeto político es frágil y está continuamente rehaciéndose, mostrando así su vulnerabilidad y dependencia histórico-social.

En las obras recientes de Butler se observa un desplazamiento conceptual que debe anotarse. En las últimas obras, Butler ya no habla tanto de "norma(s)" como de "marco(s)". Así habla de "marcos de guerra" (2009). Entiende por marco, "categorías, convenciones y normas que preparan o establecen a un sujeto para el reconocimiento, que inducen a un sujeto de este género, preceden y hacen posible el acto de reconocimiento propiamente dicho. En este sentido, la reconocibilidad precede al reconocimiento" (BUTLER 2009 , p. 19). La categoría de "marco" significaría lo que antes Butler ha llamado "norma", pero además incluiría las prácticas y convenciones sociales que concretan la misma norma. El marco tiene la misma función que anteriormente desempeñaba la norma, como campo limitador de la "legibilidad" o la representación socio-política; lo que Butler llama ahora "reconocibilidad". Dicha reconocibilidad sería previa a cualquier posibilidad de reconocimiento, en el sentido que el primero marca el campo de lo que puede aparecer y reivindicar reconocimiento. En este sentido, Butler insiste en que hay una dimensión política previa a las discusiones sobre el reconocimiento. Dimensión que marca y posibilita la aparición de los sujetos de reconocimiento. Así, los marcos producen y estabilizan normas de reconocibilidad. "Las normas de reconocibilidad preparan el camino al reconocimiento, los esquemas de inteligibilidad condicionan y producen normas de reconocibilidad" (Ibíd., p. 21). Se trata de una dimensión ontológico-epistemológica política que limita y encuadra el campo del poder y de la política. En este sentido, la ontología y la epistemología se politizan, al producir, conducir, condicionar o delimitar ciertas reivindicaciones de reconocimiento.

Esto no significa que se suprima la realidad y se sustituya por el discurso, como si éste tuviese capacidades mágicas de producir y alterar a su antojo la realidad. Más bien lo que pretende mostrar Butler es que la realidad ya está 
condicionada políticamente desde el momento que aparece como tal. Insiste en declarar que "el hecho de que estos debates existan, y sigan existiendo, no implica que la vida y la muerte sean consecuencias directas del discurso (conclusión absurda). Más bien, implica que no existe la vida ni la muerte sin que exista también una relación a un marco determinado" (Ibíd., p. 22). El marco que pretende mapear o tornar cognoscible la realidad social no determina del todo aquello que es reconocible. Hay algo que se le escapa al marco. Algo excede al marco, en tanto que la realidad es más amplia que el marco que la pretende limitar o encuadrar. Este algo que está fuera y que al mismo tiempo constituye el propio marco, es lo que perturba constantemente nuestro sentido de la realidad, lo altera, lo desestabiliza (Ibíd., p. 24). Así, el marco de reconocibilidad queda supeditado a su capacidad para resolver, integrando o excluyendo aquello que está fuera y que lo altera continuamente. En este sentido, el éxito y la funcionalidad del marco dependen de su capacidad para reproducirse socialmente. Acontecimientos o nuevas relaciones alteraran y pueden romper el marco de reconocibilidad.

\section{LO HUMANO Y LA DESHUMANIZACIÓN}

La categoría de "lo humano" ha funcionado como una norma o marco. Lo humano es aquello que designa una "vida vivible y una muerte lamentable" (BUTLER 2004a, p. 183). Una vida vivible, lo que históricamente ha recogido el concepto de dignidad, es aquella que es susceptible de ser llorada y generar "duelo". "Así pues, la capacidad de ser llorado es un presupuesto para toda la vida que importe" (BUTLER 2009, p. 32). Lo humano se refiere a un tipo de vida, que desborda lo biológico-dado, y que es vivible dentro de unos parámetros socio-político determinados. Hay vidas humanas vivibles e invivibles, es decir, cuya muerte es incapaz de generar ningún tipo de lamento o duelo. Una vida que no importa, una vida no humana. En este sentido somos capaces de enhebrar la serie de acontecimientos que introducen dicho trabajo. ¿Cuál es el denominador común entre el maltrato a los inmigrantes, la exclusión de sus derechos sanitarios, sociales y políticos, la violencia de género, el aumento de la xenofobia y el racismo, etc.? El denominador común se halla en nuestro propio marco de lo humano y lo no humano.

La diferenciación entre aquello que es humano y aquello que no es humano es una diferenciación contingente y cambiante históricamente, que estructura y determina tanto a los sujetos como a las instituciones y prácticas sociales. 
Como marco ha marcado los límites de la reconocibilidad, es decir las condiciones de posibilidad para cualquier otro tipo de reclamación de reconocimiento. Solo puede reclamar reconocimiento aquello que previamente es visto y percibido como sujeto u objeto con capacidad de ser reconocido. El marco de lo humano se ha estructurado a partir de la exclusión histórica de lo que no es humano. Dicha diferenciación que enmarca la exclusión de minorías es una práctica o diferenciación de poder. "La categoría de lo "humano" retiene en sí misma la elaboración del poder diferencial de la raza como parte de su propia historicidad (...). Que la categoría se elabore en el tiempo y que funcione a través de la exclusión de una amplia serie de minorías significa que su rearticulación se iniciará precisamente en el momento en el que los excluidos hablen a o desde dicha categoría" (BUTLER 2004b, p. 30). Lo que es excluido del marco, lo no humano es lo que altera constantemente la existencia del propio marco, la existencia de dicha diferenciación. El aumento de la inmigración o el empoderamiento de ciertos sectores de la sociedad son vistos como desafíos que alteran los marcos de lo reconocible como humano. En este sentido solo cabe dos posibilidades, bien la reafirmación violenta del marco de cara a su estabilización, o bien el cuestionamiento crítico y su transformación por ampliación de aquello conceptuado previamente como no humano. Políticas de afirmación o de transformación de los marcos.

Pero más allá de las formas políticas que producen los acontecimientos, cabe destacar como funciona el marco de lo humano; es decir la diferenciación entre aquello que es humano y aquello que no es humano. Según Butler, estos esquemas de reconocibilidad de lo humano no siempre funcionan produciendo ideales de aquello que es humano y aquello que no es humano. "A veces, producen imágenes de lo que es menos que humano bajo el aspecto de lo humano para mostrar el modo como lo inhumano se oculta, amenazando con engañar a todos aquellos que sean capaces de creer que allí, en esa cara, hay otro rostro humano. Pero a veces, este esquema normativo funciona precisamente substrayendo toda imagen, todo nombre, toda narratividad, de modo que nunca hubo allí una vida ni nunca hubo allí una muerte" (BUTLER 2004a, p. 183). Lo humano se reafirma a partir de la representación de lo no humano. La deshumanización del otro es condición de posibilidad de lo humano. Esta deshumanización se consigue bien enfatizando aquellas actitudes o hechos que se sitúan más allá de lo humano, para mostrar que no todo lo que parece humano lo es. Es decir, mostrar la inhumanidad que se esconde detrás de cualquier ser humano, manifiesta la necesidad de la exclusión o 
diferenciación entre aquellos que son o deben considerarse humanos y aquellos que no. En este punto cabe recordar las declaraciones del Ministro del Interior del Gobierno del Estado español sobre el uso de pelotas de goma por parte de la guardia civil para proteger la frontera de Ceuta. En ellas Fernández Díaz insistió en el uso legítimo que hizo la guardia civil de sus instrumentos de cara a repeler a la "violencia inaudita de los inmigrantes". ${ }^{1}$ Estas declaraciones no hacen sino reforzar la idea de inhumanidad de los inmigrantes, para luego poder justificar y legitimar el uso de la violencia sobre y contra ellos. Violencia que en principio debería no ser utilizada para relacionarse con seres propiamente humanos y "civilizados". Dicho término puede ser entendido como sinónimo de humano en este contexto.

La otra vía para marcar la frontera política entre lo humano e inhumano es la de borrar todo rastro de humanidad de la vida excluida del ámbito de lo humano. La historia personal, los afectos y hasta el nombre desaparecen como mecanismos de deshumanización. Los inmigrantes pasan a ser una masa homogénea e indiferenciada, donde todos son iguales, sin pasado, sin familia, ni sentimientos ni afectos. Ésta vía de deshumanización se explicita cuando los inmigrantes fallecidos en el estrecho de Gibraltar o delante de las costas italianas son sepultados sin nombre y con la simple inscripción del día de su fallecimiento, sin ser llorados, ni añorados por nadie. Es la más alta deshumanización. La vida se reduce a vida simplemente biológica.

La deshumanización permite, posibilita y legitima el ejercicio de la violencia sobre los grupos deshumanizados o excluidos de la propia definición de lo humano. Así, se puede hablar de "marcos de guerra", en el sentido de aquellos marcos que permiten discernir la posibilidad de la guerra para contener a los no humanos y que éstos no alteren la vida humana, la vida vivible. La guerra y la violencia se convierten en una necesidad frente aquello que la puede alterar o desestabilizar. En relación a la guerra de Irak, Butler afirma: "Trágicamente parece que los Estados Unidos buscan prevenir la violencia contra ellos ejerciéndola por adelantado, pero la violencia que temen es la violencia que engendran" (BUTLER 2004a, p. 186). La violencia se convierte en algo ambivalente. Por una parte es un "recurso civilizador", en el sentido de mantener y estabilizar la distancia entre aquello que es humano y aquello que no lo es. Pero al mismo tiempo, engendra lo inhumano. Muestra el rostro deshumanizador de los que se auto-perciben como propiamente humanos. Por

${ }^{1}$ El diario, $13 / 02 / 2014$. 
ello, la violencia parte siempre de la deshumanización, produciendo inhumanidad. Caso paradigmático ha sido la guerra de Gaza del pasado verano, donde el número de víctimas infantiles y civiles del conflicto se han justificado precisamente para mantener las condiciones de vida vivibles de los ciudadanos de Israel (vidas sin bombardeos de cohetes por parte de las milicias de Hamás).

\section{APERTURA CRÍTICO-POLÍTICA DE LO HUMANO; PRECARIEDAD Y PRECARIDAD}

Frente al devenir funesto de la violencia y la barbarie actuales cabe recordar que estos mismos acontecimientos que se producen en el marco de la diferenciación entre lo humano y lo no humano, lo desestabilizan. Muestran los quiebros y las injusticias que producen dicho marco. La crítica al marco abre la puerta a su superación por la vía del reconocimiento de la igualdad de la precariedad humana. La desestabilización crítica de las normas y el marco de reconocibilidad de lo humano requieren una nueva ontología social y política. Ontología que entienda a los seres humanos como seres que aspiran a una vida vivible, una vida que valga la pena ser vivida; como seres precarios, sufrientes $y$ vulnerables. La precaridad de la vida implica "vivir socialmente, es decir, el hecho de que nuestra vida está siempre, en cierto sentido, en manos de los otros; e implica también estar expuestos tanto a quienes conocemos como a quienes no conocemos, es decir, la dependencia de unas personas que conocemos, o apenas conocemos de nada" (BUTLER 2009, p. 30). Reconocer la vida como precaria significa reconocerla como frágil, expuesta y vulnerable a los demás, es decir, incontrolable en cierta manera por el yo. Una vida dependiente e interdependiente de los demás. Precisamente por ser la vida humana precaria, ésta debe ser cuidada responsablemente por los demás. Se abre la puerta a la necesidad de repensar la ética moderna universalista basada en la idea del individuo independiente y el universalismo sustentado en el "otro genérico", por una ética del cuidado y la responsabilidad. Ética que parta del hecho de que los seres humanos son seres interdependientes y vulnerables, y orientada por un universalismo interactivo, "que reconoce la pluralidad de modos de ser humano y las diferencias entre seres humanos, sin avalar todas estas pluralidades y diferencias como válidas moral y políticamente” (BENHABIB 1992, p. 176).

La precariedad es una condición compartida por todos los seres humanos vivos; en este sentido nos hace radicalmente iguales. Pero, al ser una condición humana limitada socialmente, se dan distribuciones diferenciales de la misma.

Análisis. Revista de Investigación filosófica, Vol. 2, n. ${ }^{\circ} 1$ (2015): 49-61 
A esta distribución diferencial de la precariedad, social y políticamente producidas, Butler la llama "precaridad". Mientras la precaridad es inducida por la distribución diferencial de riqueza y reconocimiento entre grupos sociales diferentes, la precariedad es constitutiva del ser humano. "El reconocimiento de la precariedad compartida introduce unos fuertes compromisos normativos de igualdad e invita a una universalización más enérgica de los derechos, que intente abordar las necesidades humanas básicas de alimentación, cobijo y demás condiciones para poder persistir y prosperar" (BUTLER 2009, p. 50). La radical igualdad ontológica que enmarca la precariedad permite una crítica normativa igualitaria contra las formas diferenciales de precaridad y sobre todo contra las formas de deshumanización e inhumanización.

Esta nueva manera de enmarcar lo humano, que pone a la vista su precariedad, fragilidad, vulnerabilidad y sufrimiento permite "defender el valor y la dignidad de la vida humana, reaccionar con indignación cuando unas vidas estén siendo degradadas o evisceradas sin consideración alguna a su valor como vidas" (Ibíd., p. 114). Una nueva ontología que proporciona una visión crítica de la realidad social, cuestionando tanto los procesos de deshumanización como las prácticas violentas de inhumanización, desde un horizonte normativo igualitarista. Entendiendo como deshumanizador todo aquello que atente contra la radical igualdad precaria de lo humano y su capacidad de ser llorados, sean procesos de distribución diferencial de bienes, derechos, de participación social y política, o de reconocimiento.

En este sentido, Butler propone un nuevo programa político de izquierdas, que supere tanto el multiculturalismo como el liberalismo político. Este programa se basa en dos ejes centrales: "En primer lugar, replantear y expandir la crítica política de la violencia estatal, incluyendo tanto la guerra como esas formas de violencia legalizadas mediante las cuales las poblaciones se ven diferencialmente privadas de los recursos básicos necesarios para minimizar la precariedad (...). En segundo lugar, habría que insistir menos en la política identitaria, o en el tipo de intereses y creencias formulados sobre la base de pretensiones identitarias, y más en la precariedad y en sus distribuciones diferenciales, con la esperanza de que puedan formarse nuevas coaliciones" (Ibíd., p. 55). Un programa político centrado en la denuncia de la violencia, entendida ésta de forma amplia y en la crítica a la ontología social liberal, que entiende a los sujetos como racionales, independientes, interesados y con una identidad ya constituida. Para Butler, debe hablarse más de identificación que no de identidad. La identificación es un proceso que continuamente se va 
rehaciendo a la luz de las nuevas condiciones sociales y políticas. Estos procesos de identificación permitirían armar "coaliciones" ${ }^{2}$ que cuestionen desde puntos de vista diferentes los marcos de definición de lo humano que permiten y legitiman la violencia, tanto estatal como social. "Sujetos políticos coaligados" que liguen las agendas políticas de diferentes movimientos sociales y políticos críticos como los movimientos contra la política bélica, a favor de la libertad sexual, en defensa de los inmigrantes, feminista, ecologista, etc. El reconocimiento de la radical precariedad humana y la distribución diferencial de la precaridad reestructura el campo político entre los que pretenden afirmar y estabilizar el marco que permite y legitima ciertas prácticas violentas, y los que lo cuestionan, más allá de las diferentes reivindicaciones que puedan defender. Aparece una nueva agenda política de izquierdas centrada en la crítica a las diferentes formas de violencia y exclusión, y el intento por rediseñar los marcos normativos desde una perspectiva igualitarista.

La propuesta de Butler es sumamente interesante ya que es capaz de ligar críticamente diferentes aspectos de la realidad social y política, y proponer cursos de acción política nuevos, igualitaristas y transaccionales a los diferentes movimientos sociales críticos. Una propuesta no basada tanto en las políticas de reivindicación, como en las políticas de redefinición de los marcos normativos socio-políticos. Políticas de redefinición que proponen un marco normativo que enfatice la precariedad humana y acentúan todas aquellas prácticas dirigidas a hacer de la vida humana una vida capaz de ser lloradas y que valga la pena; es decir, el cuidado, la responsabilidad, el deseo, el amor, la solidaridad, etc.

A modo de conclusión, hay que señalar tres límites tanto a la propuesta como al programa político butleriano. En primer lugar, tanto la ontología de la precariedad como la crítica al marco excluyente que limita lo humano a ciertos grupos sociales pivotan sobre el concepto de vida. Éste es sumamente genérico, queda poco definido y discursivamente ha estado más próximo a proyectos políticos conservadores y reaccionarios que defienden la vida como algo ya dado, constituido y cerrado. Evidentemente ésta no es la visión que

${ }^{2}$ En este punto Butler parece coincidir con N. Yuval-Davis y con Ch. Mouffe. Yuval-Davis habla de la necesidad de rearticular "políticas transversales», mientras que Mouffe propone una «interpretación democrática radical de la ciudadanía» basada en el establecimiento de equivalencias entre agentes que denuncian relaciones de poder asimétricas y con agentes que hagan reivindicaciones igualitarias y emancipadoras (MOUFFE 1993, p. 24; YUVAL-DAVIS 2010, p. 182).

Análisis. Revista de Investigación filosófica, Vol. 2, n. ${ }^{\circ} 1$ (2015): 49-61 
tiene Butler, pero se requiere un análisis más detallado del concepto. En segundo lugar, su crítica a la violencia tanto estatal como social es sumamente genérica. No entra a hacer un análisis de las formas estatales y sociales de la violencia. Va citando algunas, pero no hay un análisis exhaustivo de las mismas. En tercer lugar, el marco epistémico-ontológico que defiende Butler al insistir en el papel preeminente que juegan las normas y los marcos sociales en la constitución del sujeto y su subjetividad, permite la crítica al marco social hegemónico y la propuesta de otro marco social alternativo. Éste establecerá diferenciaciones que también provocaran exclusiones. En este sentido la exclusión es inherente e insuperable al marco. Por tanto, ¿cómo se puede defender un nuevo marco radicalmente igualitarista? ¿No es un oxímoron, una contradicción en términos? Éstas y otras cuestiones dejan abierto el debate y la propuesta de J. Butler.

Tomeu Sales Gelabert

Universitat de les Illes Balears

Tomeu.sales@uib.es

\section{BIBLIOGRAFÍA}

AgrA, M.X. (2013): "Vulnerabilidad: injusticias y cuidados", en Margarita Boladeras (ed.), Bioética: Justicia y vulnerabilidad. Barcelona: Editorial Proteus, pp. 49-82.

BENHABIB, S. (1992): El ser y el Otro en la ética contemporánea. Feminismo, comunitarismo y posmodernismo, Barcelona: Gedisa, 2006.

Butler, J, (2004a): Vida precaria. El poder del duelo y la violencia, Buenos Aires: Paidós, 2006.

BUTLER, J. (2004b): Deshacer el género, Barcelona: Paidós, 2012.

ButLer, J. (2009): Marcos de guerra. Las vidas lloradas, Barcelona: Paidós, 2010.

De Miguel, A (2005): "La violencia de género: la construcción de un marco feminista de interpretación", en Cuadernos de Trabajo Social, vol., 18.

FRASER, N. (2008): Escalas de la justicia, Barcelona: Herder.

MOUfFe, CH. (1993): El retorno de lo político. Comunidad, ciudadanía, pluralismo y

democracia radical. Barcelona: Paidós, 1999.

YUVA-DAVIS, N. (2010): "Etnicidad, relaciones de género y multiculturalismo", en Nación, diversidad y género. Perspectivas críticas, Barcelona: Anthropos. 